\title{
Progressive massive fibrosis and simple pneumoconiosis in ex-miners
}

\author{
W M MACLAREN AND C A SOUTAR \\ From the Institute of Occupational Medicine, Edinburgh EH8 9SU, UK
}

ABSTRACT A group of 17738 working miners, medically examined during 1953-8, were followed up from 1974 to 1980 . Of the 7118 men re-examined, 2547 were still working miners and 4526 had left the industry (45 were of unrecorded status). The incidence of progressive massive fibrosis (PMF) over an average follow up period of 22 years among men who had remained in the industry was 27 per 1000 , but 94 per 1000 among men who had left. This difference was only partly related to the difference in age between the groups; for men without simple pneumoconiosis at the start of the period, and for similar age groups (45-64), the attack rate in miners was 20 per 1000 and in the ex-miners 41 per 1000. In a group of 1902 leavers who did not have PMF at a medical examination conducted at most four years before leaving, 172 had developed PMF by the time of the follow up examination. Of these, 116 had had simple pneumoconiosis at the earlier examination. Cumulative exposure to respirable dust, category of simple pneumoconiosis, and age were each found to influence the probability of developing PMF in a subgroup of the 1902 men. Among the 1902 leavers, there was no overall progression or regression of simple pneumoconiosis.

Over the past 20 years, the prevalence of progressive massive fibrosis (PMF), the potentially disabling form of coalworkers' pneumoconiosis, among working British coalminers has declined steadily $(0 \cdot 7 \%$ in 1963 to $0.2 \%$ in 1981 in one large sample). ${ }^{1}$ This decline probably results in part from stringent measures to reduce concentrations of respirable dust underground. These figures are for men working in the coal industry, and the extent to which PMF occurred among men who had left coalmining was not known. Similarly, recent studies of the incidence of PMF have been based only on working miners, ${ }^{23}$ though one study published over 20 years ago included exminers. ${ }^{4}$

We have recently completed a study of men who worked in the British coal industry in the 1950s, and who were followed up and if possible examined 22 years later, whether or not they were still working in the industry. In the present paper we compare the incidence of PMF among men who left the industry with that among men who remained. We also examine whether PMF appeared for the first time, or simple pneumoconiosis progressed or regressed, after occupational exposure to dust had ceased. Finally, in

Received 18 February 1985

Accepted 25 March 1985 a preliminary analysis, we study the influence of age, dust exposure, simple pneumoconiosis, and geographical region on the incidence of PMF in a subgroup of $\rightleftharpoons$ men who have left the industry.

\section{Methods}

The first round of the British National Coal Board's pneumoconiosis field research surveys was conducted at 24 collieries spread over the British coalfield from 1953 to 1958. The location of these colleries has been described previously. ${ }^{5}$ A sample of the men examined during this round of surveys (called the follow up sample) was selected and those who were successfully traced and who consented to take part were reexamined between 1974 and 1980, during the so called follow up round of surveys.

The total number of men examined during the first round of PFR surveys was 31 676. Each man had a full size chest radiograph taken, and so called definitive classifications $^{6}$ of these radiographs according to the International Labour Office (ILO) classification of $1950^{7}$ were available when the follow up sample was chosen. The follow up sample itself consisted of all men whose chest radiographs were classified as category 1 or greater pneumoconiosis on the ILO scale (3645 men) and about half the remainder (14093 men), randomly selected within strata determined by 
colliery and five year age groups, the proportions allocated to strata being those found in the total of 31676 men. The total size of the follow up sample was 17738 men. Men in the follow up sample who had died by the time of the follow up round of surveys were identified by methods described in a recent mortality study. ${ }^{8}$ The remaining men were traced if possible by various search procedures ${ }^{9}$ and all those traced were invited to take part in the study.

All men who took part in the study were therefore examined at least twice, between 1953 and 1958 and again between 1974 and 1980 . In addition, many were examined during the intervening period, since second and third rounds of medical surveys were carried out at all 24 collieries in 1957-63 and 1963-8 respectively, and fourth and fifth rounds at 10 out of the 24 in 1970-3 and 1973-7.

All the chest radiographs obtained at follow up survey were read by a panel of five readers (four of whom were not medically qualified) who had trained themselves to classify chest radiographs according to the 1972 ILO U/C classification. ${ }^{10}$ Readings of simple pneumoconiosis by this panel (called the self trained panel) have been shown to be reproducible, and their classifications in other studies have confirmed relations of dust exposure with radiographic appearances that had been shown or suggested in earlier readings by medically qualified readers experienced in classifying the appearances of pneumoconiosis. ${ }^{11}$ All films were read one at a time, and in random order. Classifications representing "panel average readings" of profusion and size of small rounded opacity and size of large opacity were obtained by using the median of the classifications provided by individual panel members. This implies that any film classified by the panel as showing large opacities has been so classified by a majority of the panel.

To investigate changes in the appearances of the chest radiographs after cessation of exposure to dust, a subset of men who had left the coal industry by the time of follow up survey was chosen. These men had left the industry at least five years before the follow up survey, but within four years of their last attended medical survey, and had not worked in a noxious or dusty environment since leaving. These constraints were applied to ensure that for each man there had been an interval of non-exposure to dust sufficiently long to allow radiological changes to occur, and that each man's penultimate radiograph could reasonably be taken as representing his radiological state on leaving the industry. This subset consisted of 1274 men who left the industry after the third medical survey, 492 after the second, and 257 after the first, a total of 2023 men. (The last survey attended by a man before leaving the industry is called his intermediate survey.) For each of these men, radiographs obtained at inter- mediate survey were read by the self trained panel.

In this group of 2023 ex-miners certain men were found by the self trained panel to have developed large opacities between the intermediate and follow up surveys. Since the epidemiological classification of chest radiographs permits the recording of large opacities when the appearance might be due to pneumoconiosis but could also be due to some other disease, the follow up survey radiographs of these men were examined by an experienced chest physician (CAS) who additionally recorded his opinion, based on all available clinical data including previous radiographs, on whether the appearances were consistent with complicated pneumoconiosis or were more likely to be the result of non-occupational disease. These readings were used to provide information on the self trained panel's ability to classify large opacities, not to modify the panel's classifications for the purposes of the analyses.

In a preliminary analysis of the influence of selected factors on the incidence of PMF in the group of 2023 ex-miners excluding those who had been classified as showing PMF at the time of their last medical survey within the industry estimates of the men's exposures to respiratory dust up to the time of follow up survey were used. Details of the calculations used in making these estimates may be found elsewhere, ${ }^{1213}$ but briefly that part of a man's exposure gained while working at one of the 24 (later 10) research collieries was obtained by summing products of hours worked in occupational groups by mean dust concentrations existing within these groups, the summation extending over groups and time. The component of dust exposure acquired before the research began, or at non-research collieries, or at one of the 14 collieries where the research was discontinued after the third medical survey, was estimated using work histories obtained at interview in conjunction with estimates of dust concentrations within broad job categories. Further details of these procedures will be reported separately.

Table 1 Means, (standard deviations in parentheses) of age and dust exposures at follow up survey for subgroups of the follow up sample. (Number of men with valid data is shown below the mean and standard deviation)

\begin{tabular}{lcc}
\hline Subgroup & $\begin{array}{l}\text { Age (years) } \\
\text { at follow up }\end{array}$ & $\begin{array}{l}\text { Respirable dust } \\
\text { exposure }\left(\mathrm{gh} / \mathrm{m}^{3}\right) \\
\text { to follow up }\end{array}$ \\
\hline Miners seen at follow up & $52 \cdot 7(7 \cdot 2)$ & $174 \cdot 5(102 \cdot 7)$ \\
survey & 2547 & 2498 \\
Ex miners seen at follow & $63 \cdot 0(10 \cdot 9)$ & $190 \cdot 6(128 \cdot 1)$ \\
up survey & 4526 & 4061 \\
Ex miners seen at follow & $64 \cdot 7(11 \cdot 6)$ & $190 \cdot 3(132 \cdot 3)$ \\
up survey and used & 2023 & 1873 \\
for calculation of & & \\
attack rates of large & & \\
opacities among men & & \\
no longer exposed to & & \\
dust & & \\
\hline
\end{tabular}


Table 2 Incidence of large opacities per 1000 men over a 22 year period between first survey and follow up survey for miners, by classification of profusion of small rounded opacities at first survey, and age at follow up survey (numbers of men in parentheses)

\begin{tabular}{llcccc}
\hline $\begin{array}{l}\text { Small rounded opacities } \\
\text { at first survey }\end{array}$ & \multicolumn{2}{l}{ Age at follow up survey } \\
\cline { 2 - 6 } & $35-44$ & $45-54$ & $55-64$ & $\geqslant 65$ & All ages \\
\hline 0 & $0(448)$ & $13(911)$ & $28(904)$ & $0(3)$ & $16(2226)$ \\
1 & $-(0)$ & $114(35)$ & $138(109)$ & $0(2)$ & $130(146)$ \\
2 & $-(0)$ & $100(10)$ & $150(40)$ & $0(1)$ & $137(51)$ \\
3 & $-(0)$ & $1000(1)$ & $500(6)$ & $-(0)$ & $571(7)$ \\
All categories & $0(448)$ & $19(957)$ & $46(1059)$ & $0(6)$ & $27(2470)$ \\
\hline
\end{tabular}

\section{Results}

EXTENT OF FOLLOW UP AND CHARACTERISTICS OF MEN EXAMINED

The follow up sample consisted of 17738 men. Of these, $34 \%$ had died by the time of the follow up survey and a further $26 \%$ could not be traced or were unwilling or unable to attend. Thus those examined ( 7118 men) constituted $61 \%$ of the survivors: 2547 of these were still working miners at follow up survey and 4526 had left the industry. The status of the remaining 45 could not be definitely ascertained because of missing or inadequate data. Examination of working survey records and colliery payroll lists indicated that the response of invited working miners was approximately $87 \%$. Table 1 shows the means and standard deviations of the examined men's ages at follow up survey and cumulative dust exposures to follow up survey. The prevalence of pneumoconiosis category 2 or 3 or PMF at the time of first survey was $2.9 \%$ among current miners who subsequently attended the follow up examinations, 9.3\% among exminers who attended, and $11 \cdot 1 \%$ among those who did not attend the follow up examinations, including those who had died.

INCIDENCE OF LARGE OPACITIES IN MINERS AND EX-MINERS

The incidence of large opacities in miners and exminers between first survey and follow up, based on "definitive" $x$ ray classifications at first survey, and the self trained panel's classifications at follow up, and excluding men with large opacities in the first survey radiograph and men with inadequate radiological data or unknown miner/ex-miner classification, is given in tables 2 and 3. The overall incidence among ex-miners (94 per thousand) was about three and a half times that among miners ( 27 per thousand); the incidence in the group as a whole was about two and a half times that in the miners. For men without simple pneumoconiosis at first survey, the incidence was higher in ex-miners than miners in comparable age groups (between 45 and 64) by a factor of approximately $2(p<0.01)$. These incidences were calculated over an average period of 22.1 years (SD 1.6 years, minimum $20 \cdot 2$ years, maximum $25 \cdot 8$ ).

INCIDENCE OF LARGE OPACITIES IN MEN NO LONGER EXPOSED TO DUST

Of the 1274 men who had left the industry after the third survey (between 1963 and 1968), 1193 had, at that survey, been found to be free of large opacities by the self trained panel. Ninety eight of these men were found to have developed large opacities by follow up survey. This corresponds to an incidence of 82 per 1000 over an average period of 11.4 years (range 8-15 years, standard deviation 1.8 years). Two thirds of the men developing PMF had had simple pneumoconiosis category 1 or greater at the time of leaving the industry. The incidence of large opacities in men who left the industry after second survey (between 1957 and 1962) was 118 per 1000 , based on 459 men over 17.2 year period (range 14-21 years, standard deviation $2 \cdot 2$ years), and that for men who left after the first survey was 80 per 1000 , based on 250 men over a $22 \cdot 2$ year period (range 20-26 years, standard deviation 1.6 years).

Table 3 Incidence of large opacities per 1000 men over a 22 year period between first survey and follow up survey for ex miners, by classification of profusion of small rounded opacities at first survey and age at follow up survey (numbers of men in parentheses)

\begin{tabular}{|c|c|c|c|c|c|c|c|}
\hline \multirow{2}{*}{$\begin{array}{l}\text { Small rounded opacities } \\
\text { at first survey }\end{array}$} & \multicolumn{7}{|c|}{ Age at follow up survey } \\
\hline & $35-44$ & $45-54$ & $55-64$ & $65-74$ & $75-84$ & $\geqslant 85$ & All ages \\
\hline $\begin{array}{l}0 \\
1 \\
2 \\
3 \\
\text { All categories }\end{array}$ & $\begin{array}{l}5(429) \\
0(2) \\
-(0) \\
-(0) \\
5(431)\end{array}$ & $\begin{array}{l}25(515) \\
120(25) \\
111(9) \\
0(1) \\
31(550)\end{array}$ & $\begin{array}{c}50(949) \\
192(151) \\
400(55) \\
500(12) \\
89(1167)\end{array}$ & $\begin{array}{l}50(1331) \\
279(269) \\
370(135) \\
476(21) \\
115(1756)\end{array}$ & $\begin{array}{l}131(320) \\
324(74) \\
444(36) \\
800(5) \\
198(435)\end{array}$ & $\begin{array}{l}50(20) \\
-(0) \\
0(2) \\
-(0) \\
45(22)\end{array}$ & $\begin{array}{c}48(3564) \\
251(521) \\
375(237) \\
513(39) \\
94(4361)\end{array}$ \\
\hline
\end{tabular}


Table 4 Numbers of men by category of profusion of small rounded opacities at intermediate and follow up surveys, for three groups of ex miners. The groups numbered 1, 2, and 3 are respectively men leaving after first, second, and third surveys

\begin{tabular}{|c|c|c|c|c|c|c|}
\hline \multirow[t]{2}{*}{ Ex miner group } & \multirow{2}{*}{$\begin{array}{l}\text { Profusion of small rounded } \\
\text { opacities at intermediate } \\
\text { survey }\end{array}$} & \multicolumn{5}{|c|}{ Profusion of small rounded opacities at follow up survey } \\
\hline & & $\overline{0}$ & 1 & 2 & 3 & All categories \\
\hline 1 & $\begin{array}{l}0 \\
1 \\
2 \\
3 \\
\text { All categories }\end{array}$ & $\begin{array}{r}190 \\
9 \\
4 \\
1 \\
204\end{array}$ & $\begin{array}{r}12 \\
7 \\
5 \\
0 \\
24\end{array}$ & $\begin{array}{r}3 \\
6 \\
9 \\
3 \\
21\end{array}$ & $\begin{array}{l}0 \\
0 \\
0 \\
1 \\
1\end{array}$ & $\begin{array}{r}205 \\
22 \\
18 \\
5 \\
250\end{array}$ \\
\hline 2 & $\begin{array}{l}0 \\
1 \\
2 \\
3 \\
\text { All categories }\end{array}$ & $\begin{array}{r}294 \\
35 \\
4 \\
0 \\
333\end{array}$ & $\begin{array}{r}28 \\
26 \\
13 \\
0 \\
67\end{array}$ & $\begin{array}{r}5 \\
16 \\
28 \\
7 \\
56\end{array}$ & $\begin{array}{l}0 \\
0 \\
1 \\
2 \\
3\end{array}$ & $\begin{array}{r}327 \\
77 \\
46 \\
9 \\
459\end{array}$ \\
\hline 3 & $\begin{array}{l}0 \\
1 \\
2 \\
3 \\
\text { All categories }\end{array}$ & $\begin{array}{r}758 \\
86 \\
17 \\
1 \\
862\end{array}$ & $\begin{array}{r}86 \\
71 \\
45 \\
1 \\
203\end{array}$ & $\begin{array}{r}15 \\
26 \\
64 \\
9 \\
114\end{array}$ & $\begin{array}{r}0 \\
2 \\
6 \\
6 \\
14\end{array}$ & $\begin{array}{r}859 \\
185 \\
132 \\
17 \\
1193\end{array}$ \\
\hline
\end{tabular}

In all, 172 men developed large opacities after leaving the industry. Their mean age was 72 (SD 8), and 36 were under 65. Lifetime dust exposures for these men were high; the mean value was $289 \mathrm{gh} / \mathrm{m}^{3}$ (SD 101). An experienced chest physician (CAS) examined 169 of these radiographs (three were not available at the time) and concluded that $82 \%$ of them showed appearances consistent with complicated pneumoconiosis, and the remainder showed evidence of other disease, probably not pneumoconiosis (radiographs for which a likely diagnosis could not be determined were deemed for these purposes to have other disease). This tended to confirm that incidences of PMF based on the self trained panel's classifications were not seriously biased upward by the inclusion of other, non-occupational disease.

PROGRESSION AND REGRESSION OF PROFUSION OF SMALL ROUNDED OPACITIES IN MEN NO LONGER EX POSED TO DUST

Changes in the profusion of the small rounded opacities of simple pneumoconiosis were also considered. Table 4 gives the numbers of men falling into the various categories of profusion at intermediate and follow up surveys. There was no evidence for differences in the prevalence of profusion of small rounded opacities between the intermediate and follow up surveys. The table also shows a high degree of symmetry about the main diagonals, suggesting equal amounts of apparent progression and regression between pairs of categories. A Chi-square test of symmetry applied to each of the three ex-miner groups separately failed to reach statistical significance $(p>$ $0 \cdot 3)$.

FACTORS INFLUENCING THE ATTACK RATES OF LARGE OPACITIES IN MEN NO LONGER EXPOSED TO DUST

Factors influencing the incidence of large opacities were studied in the three groups of men no longer exposed to dust, those leaving after the first, second, and third surveys. Increasing trends in incidence with lifetime dust exposure, age at follow up, and category of profusion of simple pneumoconiosis were apparent. Tables 5 and 6 show the trends in incidence with category of simple pneumoconiosis and with dust

Table 5 Incidence of large opacities per 1000 men over an 11 year period between third survey and follow up survey, for ex miners leaving after third survey, by category of profusion of small rounded opacities at third survey (numbers of men in parentheses)

\begin{tabular}{llllll}
\hline $\begin{array}{l}\text { Profusion of small rounded opacities } \\
\text { at third survey }\end{array}$ & 0 & 1 & 2 & 3 & All categories \\
\hline Incidence & $37(859)$ & $168(185)$ & $205(132)$ & $471(17)$ & $82(1193)$ \\
\hline
\end{tabular}

Table 6 Incidence of large opacities per 1000 men over an 11 year period between third survey and follow up survey, for ex miners leaving after third survey, by dust exposure to follow up survey (numbers of men in parentheses). Because of unreliable dust exposure data, 54 men were excluded from this table

\begin{tabular}{lllllllllll}
\hline $\begin{array}{l}\text { Dust exposure } \\
\left(\mathrm{gh} / \mathrm{m}^{3}\right)\end{array}$ & $0-50$ & $50-100$ & $100-150$ & $150-200$ & $200-250$ & $250-300$ & $300-400$ & $400-500$ & $\geqslant 500$ & $\begin{array}{l}\text { All } \\
\text { exposures }\end{array}$ \\
\hline Incidence & $9(113)$ & $16(192)$ & $40(177)$ & $64(141)$ & $78(141)$ & $131(130)$ & $199(166)$ & $183(60)$ & $0(60)$ & $81(1139)$ \\
\hline
\end{tabular}


Table 7 Predicted incidence of large opacities per 1000 men over 11 years, based on a model derived from 1193 ex miners who left after third survey

\begin{tabular}{|c|c|c|c|c|}
\hline \multirow{2}{*}{$\begin{array}{l}\text { Category of profusion of small } \\
\text { rounded opacities at third survey }\end{array}$} & \multirow{2}{*}{$\begin{array}{l}\text { Dust exposure }\left(g h / m^{3}\right) \text { to } \\
\text { follow up survey }\end{array}$} & \multicolumn{3}{|c|}{ Age at follow up survey (years) } \\
\hline & & 55 & 65 & 75 \\
\hline $\begin{array}{l}1 \\
2\end{array}$ & $\begin{array}{l}150 \\
250 \\
150 \\
250 \\
150 \\
250 \\
150 \\
250\end{array}$ & $\begin{array}{r}18 \\
23 \\
76 \\
93 \\
83 \\
102 \\
247 \\
293\end{array}$ & $\begin{array}{r}29 \\
37 \\
117 \\
143 \\
128 \\
156 \\
348 \\
402\end{array}$ & $\begin{array}{r}47 \\
58 \\
178 \\
214 \\
192 \\
231 \\
465 \\
522\end{array}$ \\
\hline
\end{tabular}

exposure for men whose intermediate survey was the third survey. (The apparent fall in incidence at very high dust exposures may be caused by a lower probability of survival for PMF cases with this level of exposure.) There was also considerable variation between geographical regions, particularly uniformly high rates in south Wales and low rates in Scotland.

The joint influence of the factors considered above on the incidence of large opacities was assessed by means of a linear logistic model in which the logistic transform of the probability of developing PMF was assumed to be a linear function of age and exposure to dust, within strata specified by geographical region and category of simple pneumoconiosis at intermediate survey. This analysis was confined to the 1193 men who left after the third survey and whose third survey radiograph was free from PMF. It was thought that for these men incidence was less likely to have been biased by non-attendance at the follow up survey. Also, estimates of dust exposure for these men were more reliable, since a smaller proportion of their individual exposures has been accumulated before

Table 8 Incidence of large opacities per 1000 men found among third survey leavers in the present study (column (iv)), together with incidences obtained in three other studies: Cochrane ${ }^{4}$ (column $\left.(i)\right)^{*}$, McLintock et al ${ }^{2}$ (column (ii) $\dagger$ and Shennan et al ${ }^{3}$ (column (iii) $\ddagger$ by either initial or average category of profusion of small rounded opacities, $\S$ with adjustments made where necessary to a follow up period of 11 years

\begin{tabular}{|c|c|c|c|c|}
\hline \multirow{2}{*}{$\begin{array}{l}\text { Category of } \\
\text { profusion }\end{array}$} & \multicolumn{4}{|l|}{ Study } \\
\hline & (i) & (ii) & (iii) & (iv) \\
\hline $\begin{array}{l}0 \\
1 \\
2 \\
3\end{array}$ & $\begin{array}{r}25 \cdot 7 \\
8 \cdot 0 \\
195 \cdot 2 \\
409 \cdot 1\end{array}$ & $\begin{array}{r}0.6 \\
24.4 \\
146.4 \\
288.8\end{array}$ & $\begin{array}{r}1 \cdot 3 \\
32 \cdot 7 \\
155 \cdot 1 \\
403 \cdot 0\end{array}$ & $\begin{array}{r}37 \cdot 2 \\
167 \cdot 6 \\
204 \cdot 6 \\
470 \cdot 6\end{array}$ \\
\hline
\end{tabular}

* See table 10 of Cochrane's paper. Figures quoted here are for separate readings of simple pneumoconiosis and paired readings of PMF.

+Personal communication from Dr M Jacobsen. Results given are derived from an unpublished table containing both numbers of men at risk and numbers of attacks, which formed the basis of table VI in paper by McLintock et $a^{2}$.

+See table 3 of paper by Shennan et al, results for men aged 35-54. ${ }^{3}$ §For studies (ii), (iii), and (iv), the initial category was used; for study (i) the average category. first survey, before the research dust sampling programme started.

The result of this analysis indicated that each of the factors, dust exposure, age, and category of profusion of simple pneumoconiosis, was related to the incidence of large opacities, allowance being made for the other two variables in each case, and also for geographical region. The variations in incidence between regions were accounted for by the effects of the other three variables; a statistical test of the parameters describing regional effects did not attain significance $(p>0 \cdot 2)$. The smallness of the sample, however, forbids the conclusion that regional variations are simply the result of differing age, dust, and pneumoconiosis distributions. Some predictions based on the logistic model are illustrated in table 7 , showing the strong influences of dust exposure, simple pneumoconiosis, and age.

\section{Discussion}

The findings reported here show that estimates of prevalence and incidence of PMF based on working miners may substantially underestimate the frequency of the condition. An estimate of the incidence of PMF over 22 years based only on the working miners in this study would have underestimated the overall incidence by a factor of about two and a half.

Probably the incomplete response rate (only $40 \%$ of the chosen sample was seen at follow up survey) has influenced the estimate of the incidence rate of PMF among ex-miners. Among men who were not examined at follow up, however, the prevalence of simple pneumoconiosis at the time of the first survey was higher than among examined ex-miners, and in both of these groups the prevalence was much higher than among the examined miners. PMF would probably follow trends similar to those of simple pneumoconiosis, in which case our estimate of the incidence of PMF in ex-miners is likely to be conservative. Furthermore, a mortality study of the same sample over a similar period has shown that in $3.7 \%$ of deaths pneumoconiosis was recorded as the primary cause. ${ }^{8}$ 
Whereas deaths from pneumoconiosis cannot be equated directly with the presence of PMF on the chest radiograph, this does indicate that advanced pneumoconiosis was relatively common among those in the sample who had died, and also suggests that despite the incomplete response rate in our study, the observed incidence among ex-miners is unlikely to be a substantial overestimate of the true incidence of PMF among men in the sample who could not be examined.

Although our study group is not representative of miners in general, since it was selected from men who working in the coal industry in the 1950 s, comparisons of attack rates within categories of simple pneumoconiosis in this and other studies show that two previous studies of working miners ${ }^{23}$ have indeed estimated lower attack rates than those found in our study. These differences may be in part attributable to the greater incidence among ex-miners, though differences between readers in interpretation of radiographic appearances, different durations of follow up, or variations due to changing working conditions may also have contributed.

The self trained, mostly non-medically qualified, panel of readers who interpreted the radiographic appearances recorded all large opacities according to the ILO classification, and thus included some appearances that were likely to result from nonoccupational disease. This has probably not greatly affected the relative magnitudes of the incidence of PMF observed among miners and ex-miners; the chest physician who reviewed 169 ex-miners' radiographs classified as showing PMF by the self trained panel thought that at least $82 \%$ of them at a conservative estimate showed appearances consistent with the disease. In any case, diagnostic difficulties may also be experienced by medically qualified readers, and we can at least be sure that in the present readings by the self trained panel no cases of PMF have been wrongly attributed to other, non-occupational diseases.

The higher incidence found in ex-miners compared with miners may indicate that in many cases men have been influenced in their decision to leave mining by their symptoms or by knowledge of their chest $x$ ray appearances. A substantial number of men, however, developed PMF for the first time after leaving the industry. This is important, since routine radiological surveillance of miners in Britain ceases when men leave the industry. Most men who developed PMF after leaving the industry did, however, have evidence of simple pneumoconiosis at the time of leaving, and a relatively much smaller proportion of men without simple pneumoconiosis subsequently developed PMF. Continued surveillance of all men with simple pneumoconiosis after they leave the industry could identify about two thirds of the cases of subsequent
PMF. In this regard, it is interesting to note that the appearance of new cases of pneumoconiosis among ex-miners in France (the retirement age for underground workers is 50) has prompted a revision of the strategy of medical prevention in that country, where ex-miners now have a chest radiograph taken every two years. ${ }^{14}$

By contrast, there was no overall progression or regression of simple pneumoconiosis after men left the industry, and whereas this does not exclude the possibility that some individuals showed real progression or regression, some of the variation shown was probably related to technical factors and reader variations.

Whereas factors influencing the development of PMF were studied in only a simple way, since a more detailed study, now completed, was currently in progress, ${ }^{15}$ the strong influences of exposure to respirable dust and of starting category of simple pneumoconiosis were confirmed, ${ }^{2-4}$ the effects of each of these factors attaining statistical significance $(p<$ 0.02 ) after allowing for the others. The apparent influence of age, noted previously, ${ }^{23}$ may partly result from an increasing effect of dust the longer it resides in the lungs. ${ }^{1315}$

Table 7 shows the magnitude of the estimated risks in relation to these factors. Because of the additive structure of the fitted equation, the tabulated dust gradient represents an average effect over all categories of simple pneumoconiosis, and therefore largely reflects the dust disease relation for category 0 men. Nevertheless, these results, while not providing a general exposure response relation, do suggest that even moderate exposures to respirable dust may be associated with an important incidence of PMF, especially in older men. (The figures of 150 and $250 \mathrm{gh} / \mathrm{m}^{3}$ chosen for table 7 cover the range of mean dust exposures in table 1 . The maximum exposure theoretically possible over a $\mathbf{3 0}$ year working lifetime under currently permitted conditions in British mines, assuming continuous working for 1631 working hours a year at coalfaces that just meet the standard, allowance being made for travelling time, may be calculated to be approximately $240 \mathrm{gh} / \mathrm{m}^{3}$.) ${ }^{16}$

A feature of other studies has been a pronounced difference in the incidence of PMF, from a low incidence in men with category 1 simple pneumoconiosis to a much higher incidence in men with category 2 or above (table 8 ). This has been used to support a policy of attempting to prevent the occurrence of PMF by keeping exposure to dust at a level consistent with low probability of developing category 2 simple pneumoconiosis. The "step up" in incidence between category 1 and 2 of simple pneumoconiosis does not appear in our results; in fact the incidence among men with category 1 is quite substantial. This finding has been corroborated by results from a recently com- 
pleted study of the incidence of PMF in a larger group of miners and ex-miners, ${ }^{15}$ and it implies that alternative criteria for preventing massive lung fibrosis may be preferable, either directed towards the prevention of category 1 simple pneumoconiosis or a dust control standard designed in the knowledge of a direct estimated exposure response relation for PMF.

We thank many of our colleagues for their contributions to this work and the miners and ex-miners who took part. We also gratefully acknowledge the work of the five members of the self trained panel: Mrs K Duncan, Dr M R Fettes, Mrs G Henderson, Mrs C Scott, and Mrs V G White.

The study was supported by the Commission of the European Communities (contract No 7246-16/8/002) and by the National Coal Board of Great Britain.

\section{References}

${ }^{1}$ National Coal Board Medical Service. Annual report 1982-83. London: National Coal Board (Medical Service), 1984.

${ }^{2}$ McLintock JS, Rae S, Jacobsen M. The attack rate of progressive massive fibrosis in British coalminers. In: Walton WH, ed. Inhaled particles III. Vol II. Old Woking (Surrey): Unwin Bros, 1971:933-52.

${ }^{3}$ Shennan DH, Washington JS, Thomas DJ, Dick JA, Kaplan YS, Bennet JG. Factors predisposing to the development of progressive massive fibrosis in coal miners. $\mathrm{Br} J$ Ind $\mathrm{Med}$ 1981;38:321-6.

${ }^{4}$ Cochrane AL. The attack rate of progressive massive fibrosis. $\mathrm{Br} \mathrm{J}$ Ind Med 1962;19:52-64.

${ }^{5}$ Rogan JM, Rae S, Walton WH. The National Coal Board's pneumoconiosis field research-an interim review. In: Davies $\mathrm{CN}$, ed. Inhaled particles and vapours II. Oxford: Pergamon Press, 1967:493-508.
${ }^{6}$ Fay JWJ, Rae S. The pneumoconiosis field research of the National Coal Board. Ann Occup Hyg 1959;1:149-61.

${ }^{7}$ International Labour Organisation. Third International Conference of Experts on Pneumoconiosis, Sydney, 1950, record of proceedings. Geneva: International Labour Office, 1953.

${ }^{8}$ Miller BG, Jacobsen M, Steele RC. Coalminers mortality in relation to radiological category, lung function and exposure to airborne dust. Edinburgh: Institute of Occupational Medicine, 1981. (IOM report No TM/81/10.)

${ }^{9}$ Melville AWT, Paris I, Hurley JF, Soutar CA. Pneumoconiosis, lung function and exposure to airborne dust: epidemiological research to compare responses of working coalminers with responses of ex-miners. Edinburgh: Institute of Occupational Medicine, 1979. (IOM report No TM/79/11.)

${ }^{10}$ International Labour Organisation. ILO U/C International classification of radiographs of the pneumoconioses 1971. Geneva: International Labour Office, 1972. (Occupational Safety and Health Series No 22.)

${ }^{11}$ Copland L, Burns T, Jacobsen M. Classification of chest radiographs for epidemiological purposes by people not experienced in the radiology of pneumoconiosis. $\mathrm{Br} J$ Ind Med 1981;38:254-61.

${ }^{12}$ Dodgson J, Hadden GG, Jones CO, Walton WH. Characteristics of the airborne dust in British coalmines. In: Walton WH ed. Inhaled particles III. Vol II. Old Woking (Surrey): Unwin Bros, 1971:757-81.

${ }^{13}$ Hurley JF, Burns T, Copland L, Dodgson J, Jacobsen M Coalworkers' pneumoconiosis and exposure to dust at 10 British coalmines. Br J Ind Med 1982;39:120-7.

${ }^{14}$ Amoudru C. Characteristiques actuelles de l'epidemiologie des pneumoconioses des mineurs de charbon dans les houilleres Francaises et consequences sur la reglementation de prevention medicale et de compensation. In: Bergbau-Berufgenossenschaft. VIth International Pneumoconiosis Conference, 1983, Bochum. Geneva: International Labour Office, 1984:84-91.

${ }^{15}$ Hurley JF, Maclaren WM, Alexander WP, et al. Factors influencing the occurrence of progressive massive fibrosis in British coalminers. Edinburgh: Institute of Occupational Medicine 1984. (IOM report No $\mathrm{TM} / 84 / 2$.)

${ }^{16}$ Jacobsen M. Coalworkers' pneumoconiosis: results from epidemiological studies in Britain. In: Bergbau-Berufsgenossenschaft. VIth International Pneumoconiosis Conference 1983, Bochum. Geneva: International Labour Office, 1984:92-102. 